\title{
NaCl tolerance in Lycopersicon pennellii introgression lines: QTL related to physiological responses
}

\author{
A. FRARY ${ }^{1}$, D. KELEŞ ${ }^{2}$, H. PINAR ${ }^{2}$, D. GÖL ${ }^{1}$ and S. DOĞANLAR ${ }^{1 *}$ \\ Department of Molecular Biology and Genetics, Izmir Institute of Technology, Urla 35430, Izmir, Turkey ${ }^{1}$ \\ Alata Horticultural Research Institute, Erdemli 33740, Mersin, Turkey ${ }^{2}$
}

\begin{abstract}
The growth and ion content of salt sensitive Lycopersicon esculentum Mill. cv. M82 and salt tolerant L. pennellii Correll accession LA716 were examined under both control and stress conditions $(150 \mathrm{mM} \mathrm{NaCl})$. L. esculentum grew more vigorously than L. pennellii under optimal conditions, however, L. pennellii was able to maintain its growth better than cultivated tomato when the plants were exposed to salinity. Sodium content of both L. esculentum and L. pennellii increased as a result of $\mathrm{NaCl}$ stress. In addition, both species showed reduced potassium and calcium content due to salinity. The physiological traits were also measured in a population of $52 \mathrm{~L}$. pennellii introgression lines grown under both normal and stress conditions. A total of 311 quantitative trait loci (QTL) were identified for the studied traits: plant height, stem diameter, leaf number, leaf and root fresh and dry mass, and sodium, potassium and calcium contents. Some of the loci (124) were identified under both control and stress conditions while 86 QTL were identified only under non-stress conditions and 101 loci were identified only under $\mathrm{NaCl}$ stress.
\end{abstract}

Additional key words: calcium, Lycopersicon esculentum, potassium, salinity, sodium, tomato.

\section{Introduction}

Salt stress tolerance is an extremely complex plant trait with multiple physiological, biochemical and genetic components (Xiong and Zhu 2002). Salinity tolerance may be expressed in more than one way including tolerance to osmotic stress, exclusion of damaging effects of sodium and chloride ions and/or tolerance to these ions (Munns and Tester 2008). When plants are first exposed to salt stress, ion homeostasis in the cell is maintained by pumping out of sodium ions at the plasma membrane and/or sequestration of these ions in the vacuole. In order to maintain growth, the plant must be able to tolerate toxic levels of sodium in its vacuoles and, at the same time, continue to take up essential ions such as potassium and calcium (Borsani et al. 2003). In addition to their roles in normal plant nutrition and metabolism, potassium and calcium are used for osmotic adjustment (Shabala and Cuin 2007) and to limit sodium entry into the cell (Demidchik and Maathuis 2007, Munns and Tester 2008) when the plant is under $\mathrm{NaCl}$ stress.
Cultivated tomato (Lycopersicon esculentum) is moderately sensitive to salinity at all stages of development (Maas 1986, Foolad 1996). At low concentrations of $\mathrm{NaCl}$, tomato is able to exclude sodium ions (Foolad 1997) and the tolerant cultivars reduce sodium and increase potassium accumulation (Juan et al. 2005). Under high salinity, however, this system breaks down and a positive correlation between plant sodium content and the extent of damage is observed (Dasgan et al. 2002). In addition, plant growth and yield suffer as a result of the osmotic and oxidative stress and nutrient deficiency. Some of the wild relatives of cultivated tomato are salt tolerant. For example, L. pennellii accession LA716 has been reported as $\mathrm{NaCl}$ tolerant in several studies (Tal and Shannon 1983, Shalata and Tal 1998, Shalata et al. 2001, Mittova et al. 2002, 2003, 2004). Tomato salt tolerance is known to be a complex trait controlled by multiple genes with development and environment-specific loci associated

Received 16 February 2010, accepted 18 May 2010.

Abbreviations: IL - introgression line; QTL - quantitative trait loci.

Acknowledgements: This research was funded by grants from the Scientific and Technological Research Council of Turkey (TUBITAK project No. TBAG 103T173), the Prime Ministry State Planning Organization of the Republic of Turkey (DPT Project No. 2003K120690) and Izmir Institute of Technology (IYTE 2003-11).

* Corresponding author; fax: (+90) 2327507509, e-mail: samidoganlar@iyte.edu.tr 
with various components of tolerance (Foolad 2004). Thus, the genetic dissection of salt tolerance is difficult; however, it is necessary for the development of salt tolerant cultivars.

In this work, an introgression line population derived from a cross between the tolerant wild species L. pennellii LA716 and cultivated tomato (Eshed and Zamir 1995) was assayed for growth response and ion

\section{Materials and methods}

Salt-sensitive Lycopersicon esculentum Mill. cv. M82, salt-tolerant wild species L. pennellii Correll ass. LA716 and 52 L. pennellii $\times$ cultivated tomato introgression lines (ILs; Eshed and Zamir 1995) were used in the experiment. The IL population provides complete coverage of the L. pennellii genome as each IL contains a single introgression from the wild species in the genetic background of L. esculentum M82 (Eshed and Zamir 1995).

Seeds were germinated in peat and grown in aerated Hoagland's nutrient solution (Epstein 1972) with six replicates of each plant line. The experiment was performed in a greenhouse under natural irradiance and day/night temperatures of $27-29 / 23-25{ }^{\circ} \mathrm{C}$ and air humidity $45-51 \%$. At the seven true leaf stage, $\mathrm{NaCl}$ treatment started with the gradual addition of $\mathrm{NaCl}$ to the nutrient solution. The first increment of $\mathrm{NaCl}$ was $25 \mathrm{mM}$ and additional increments of $25 \mathrm{mM} \mathrm{NaCl}$ were added each day until the $\mathrm{NaCl}$ concentration reached $150 \mathrm{mM}$. The plants were grown for $15 \mathrm{~d}$ at $150 \mathrm{mM} \mathrm{NaCl}$. After the treatment period, plant height, stem diameter, and leaf number were determined for each plant. The leaves and roots were harvested and combined for each line to determine leaf and root fresh mass $(\mathrm{g})$. After drying at $65{ }^{\circ} \mathrm{C}$ for $48 \mathrm{~h}$, leaf and root dry mass were also determined. Additionally, leaf samples were analyzed for sodium, potassium and calcium content using the methods described by Chapman and Pratt (1961).

Student's $t$-test was used to compare treatment means for the parental lines and ILs at $P<0.05$. The mean of content under both control conditions and $\mathrm{NaCl}$ stress. Because these lines are genetically characterized, it was possible to identify and map genes related to plant growth and ion accumulation in response to $\mathrm{NaCl}$ stress. These loci may be useful for an increased understanding of plant salt tolerance and the future development of salt tolerant tomato cultivars. each IL was compared with the mean for M82 under both control and stress conditions with this value expressed as a percentage (IL control mean/M82 control mean $\times 100$ ). This value was then used to determine the difference in effect seen in the IL as compared to M82. This comparison with M82, the genetic background of the ILs, allowed the difference in effect to be attributed to the particular introgression carried by the IL. For this calculation, M82 was set as $0 \%$ and $100 \%$ was subtracted from the percent obtained for each IL. Thus, a value of $50 \%$ in an IL would indicate that the introgression caused a $50 \%$ increase in the trait as compared to M82. For detection of QTL, a threshold of $30 \%$ was used. Thus, a QTL was assumed to be located in a particular introgression only if that introgression were associated with a $30 \%$ change in the trait as compared to M82. The use of a $30 \%$ threshold was chosen so that only QTL with large effects would be identified and agrees with the threshold used by Rousseaux et al. (2005) and Frary et al. (2011) in similar QTL detection studies in the IL population. Loci identified in only one of the treatments (control or $\mathrm{NaCl}$ ) were assumed to be control- or NaCl-specific, respectively. QTL detected in both treatments were assumed to be important in controlling the trait of interest under both non-stress and stress conditions. QTL were located on the tomato map using the available IL molecular marker map (http://www.sgn.cornell.edu).

\section{Results}

Salt stress negatively affected all of the growth parameters measured in tomato cultivar M82 with the greatest decreases seen for root mass (Table 1). In L. pennellii, however, $\mathrm{NaCl}$ stress resulted in increases in plant height (1.2-fold) and stem diameter (1.3-fold) but decreases in the leaf and root traits. Leaf mass showed a greater negative response to $\mathrm{NaCl}$ stress in LA716 than M82 while root mass was more affected by stress in M82. Physiological parameter means for the ILs resembled M82 more than LA716 under both normal conditions and $\mathrm{NaCl}$ stress. Nevertheless, the ranges of values for these

traits in the ILs usually spanned and exceeded the mean parental values. $\mathrm{NaCl}$ stress negatively affected growth in most of the ILs, however, for every trait, at least a small percentage of plants showed increased growth under stress (Table 1).

Ion content of M82 and LA716 showed similar responses to $\mathrm{NaCl}$ stress: sodium content increased while potassium and calcium contents decreased (Table 1). Despite this general similarity, LA716 showed much greater increases and decreases in sodium and potassium contents, respectively, than M82. As with the growth 
parameters, ion content of the ILs exceeded the values of M82 and LA716. In addition, a significant proportion of the ILs had the opposite ion responses to $\mathrm{NaCl}$ stress as compared to their parents.

Table 1. Growth characteristics and ion content of M82, LA716 and IL lines under control conditions and NaCl stress. For the ILs, $\mathrm{NaCl}$ effect is the percentage of ILs showing increases and decreases in each parameter under $\mathrm{NaCl}$ stress as compared to non-stress conditions. Means $\pm \mathrm{SE}, n=6$.

\begin{tabular}{lccccccc}
\hline Parameter & $\begin{array}{l}\text { M82 } \\
\text { control }\end{array}$ & $\mathrm{NaCl}$ & $\begin{array}{l}\text { LA716 } \\
\text { control }\end{array}$ & $\mathrm{NaCl}$ & $\begin{array}{l}\text { ILs } \\
\text { control }\end{array}$ & $\mathrm{NaCl}$ & $\mathrm{NaCl}$ effect \\
\hline Plant height [cm] & $32.3 \pm 3.7$ & $23.7 \pm 1.9$ & $22.5 \pm 4.0$ & $18.3 \pm 1.7$ & $41.19 \pm 1.57$ & $31.36 \pm 1.26$ & $2 \%$ \\
Stem diameter [mm] & $6.7 \pm 0.3$ & $4.5 \pm 0.3$ & $4.1 \pm 0.6$ & $3.1 \pm 0.4$ & $5.03 \pm 0.1$ & $5.08 \pm 0.12$ & $17 \%$ \\
Leaf number & $9.0 \pm 0.6$ & $7.3 \pm 0.3$ & $11.0 \pm 0.0$ & $9.7 \pm 0.3$ & $8.80 \pm 0.2$ & $7.70 \pm 0.2$ & $9 \%$ \\
Leaf f.m. [g] & 12.54 & 10.03 & 5.53 & 1.52 & $21.67 \pm 1.04$ & $14.08 \pm 0.81$ & $8 \%$ \\
Leaf d.m. [g] & 1.52 & 1.10 & 0.47 & 0.15 & $1.34 \pm 0.1$ & $0.72 \pm 0.08$ & $10 \%$ \\
Root f.m. [g] & 38.42 & 14.23 & 4.03 & 2.76 & $18.24 \pm 0.78$ & $18.62 \pm 1.04$ & $58 \%$ \\
Root d.m. [g] & 1.68 & 0.25 & 0.16 & 0.18 & $0.53 \pm 0.04$ & $0.51 \pm 0.05$ & $42 \%$ \\
Na ${ }^{+}$[\% d.m.] & 1.59 & 4.24 & 0.14 & 0.77 & $0.35 \pm 0.008$ & $1.47 \pm 0.18$ & $96 \%$ \\
$\mathrm{~K}^{+}$[\% d.m.] & 3.74 & 3.27 & 4.55 & 0.49 & $5.08 \pm 0.25$ & $3.09 \pm 0.26$ & $8 \%$ \\
$\mathrm{Ca}^{2+}$ [\% d.m.] & 1.64 & 0.34 & 3.22 & 0.78 & $1.82 \pm 0.11$ & $1.57 \pm 0.13$ & $47 \%$ \\
\hline
\end{tabular}

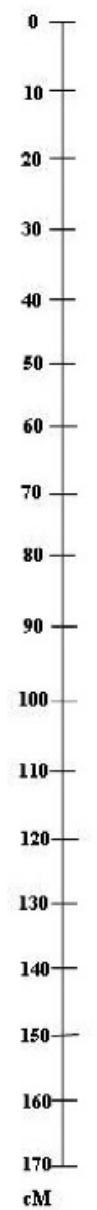

cM

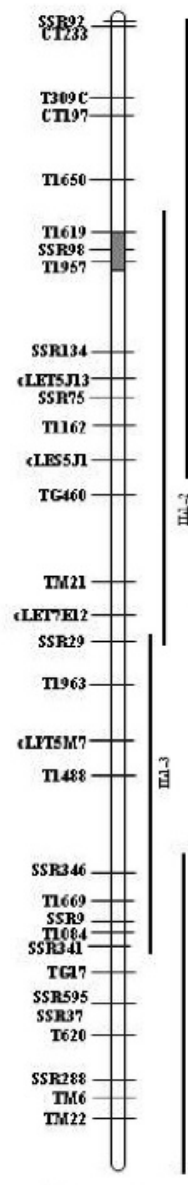

Clurom.1

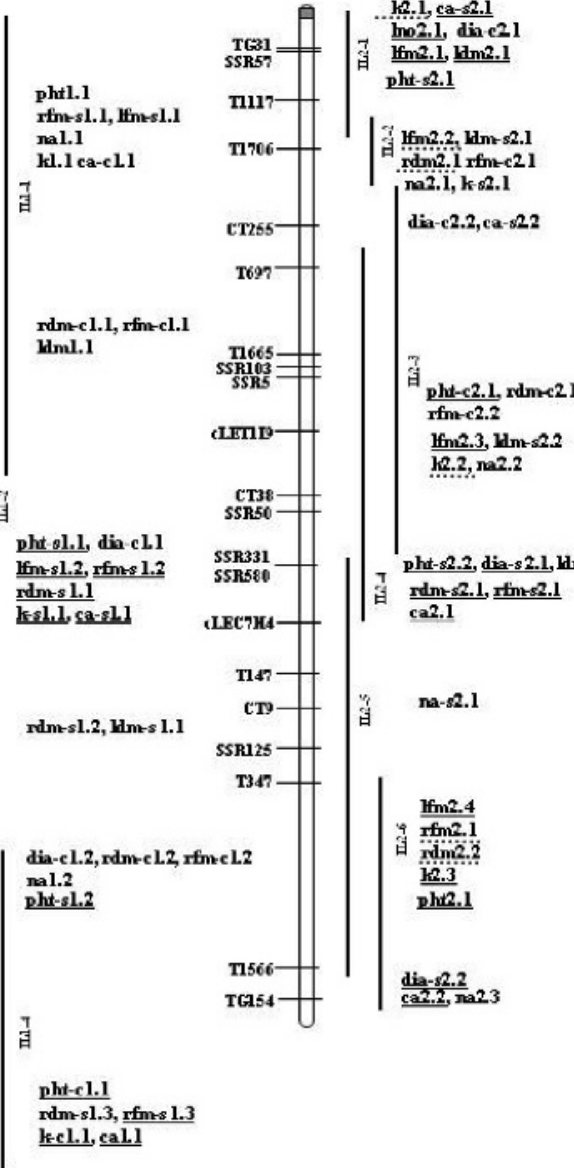

Chrom.2

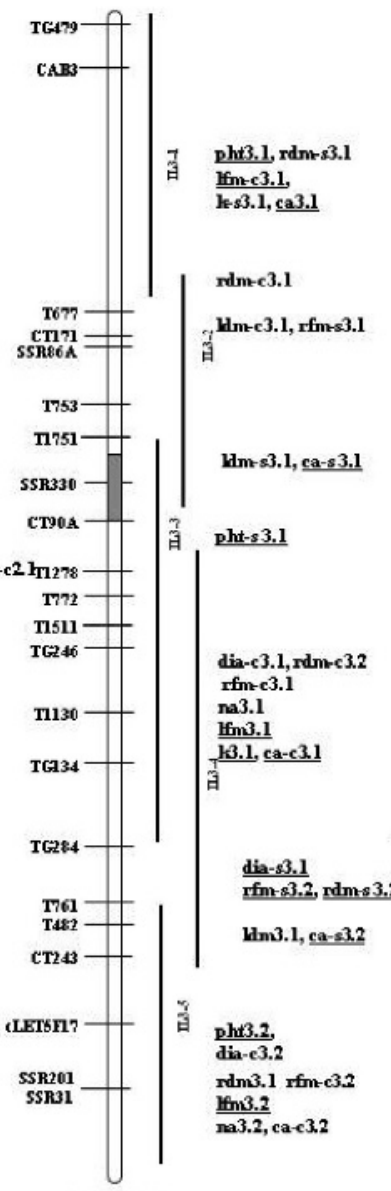

Chrom. 3

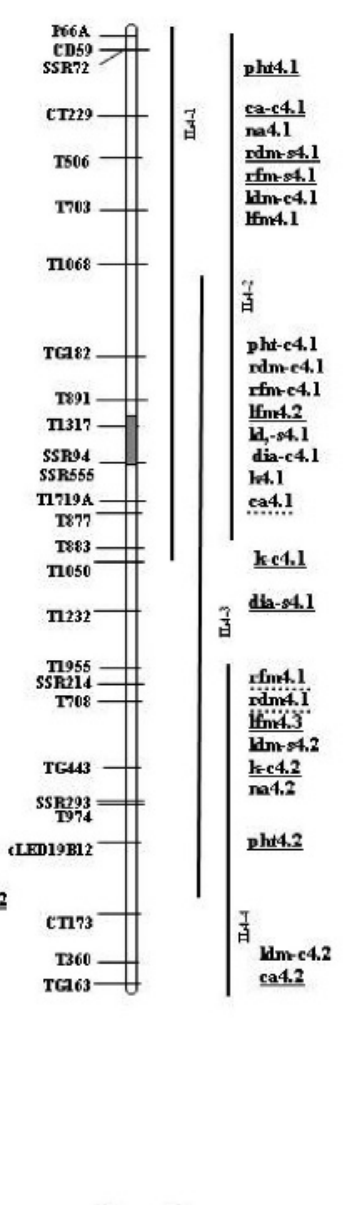

Chrom.4

Fig. 1. Linkage map for the IL population showing the locations of QTL identified in this work. For loci that are underlined, L. pennellii alleles were associated with increased growth/ion content. Wild alleles for non-underlined loci were associated with decreased growth/ion content. Dotted underline indicates that the wild alleles were associated with both increased and decreased growth/ion content, depending on the environment (control or $\mathrm{NaCl}$ ). 


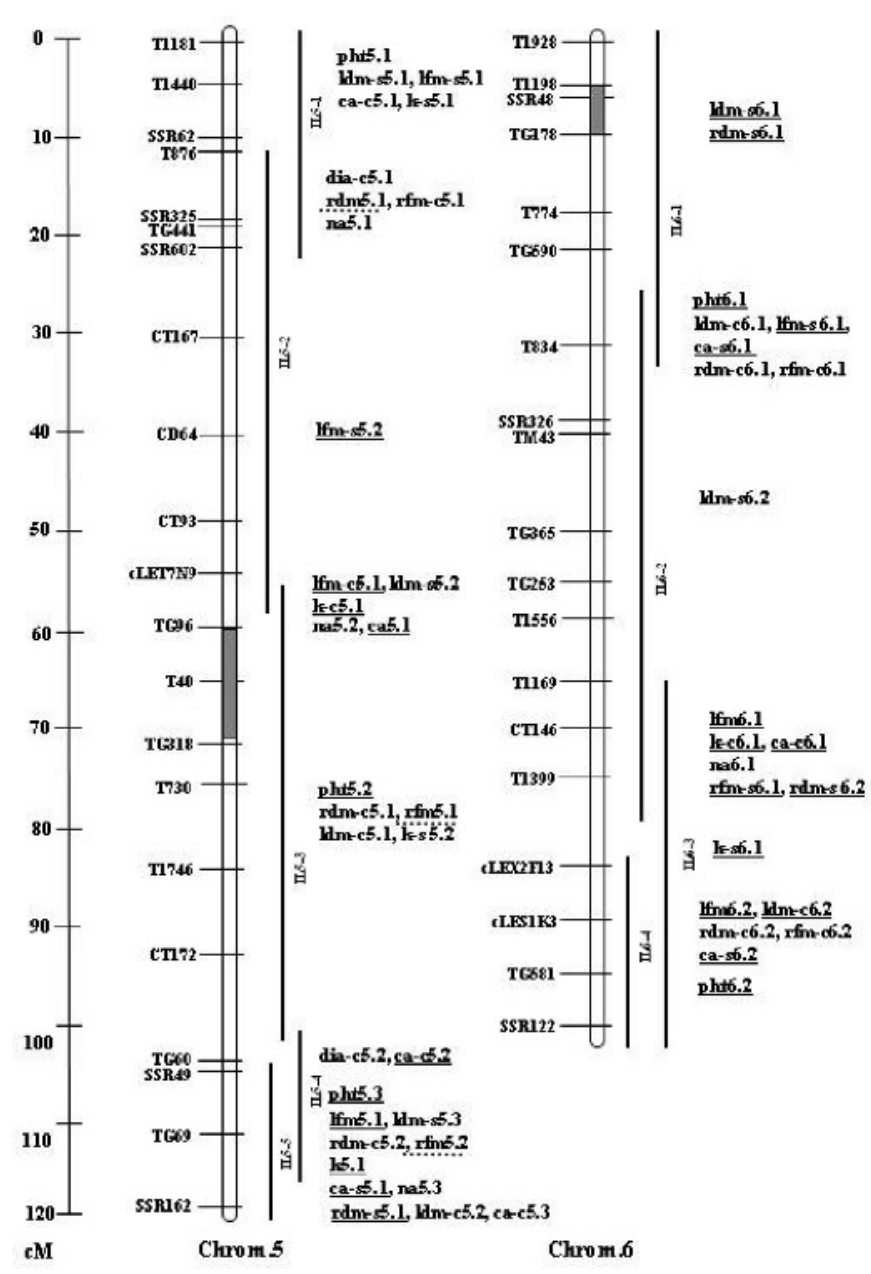

Fig. 1 (continued).

A total of 21 QTL altered plant height under both control and stress conditions in the ILs (Fig. 1). L. pennellii alleles for most of these loci $(81 \%)$ were associated with increases in plant height under both normal and stress conditions. The QTL with the strongest effect was pht2.1 for which the wild alleles were associated with 71 and $78 \%$ increases in plant height under control and stress conditions, respectively. In general, individual loci showed similar magnitudes of effect in stress and non-stress environments. Three QTL were identified for plant height under control conditions. For two of the loci, L. pennellii alleles were associated with increases in height. Six loci were detected that controlled height specifically under $\mathrm{NaCl}$ stress. L. pennellii alleles increased plant height under $\mathrm{NaCl}$ stress for five of the loci.

No QTL were detected that significantly affected stem diameter under both control and stress conditions. However, 13 loci were identified for stem diameter under control conditions (Fig. 1). L. pennellii alleles for these QTL were associated with decreased stem diameter. In addition, 8 loci were detected for stem diameter under $\mathrm{NaCl}$ stress. Interestingly, in contrast to the control QTL,

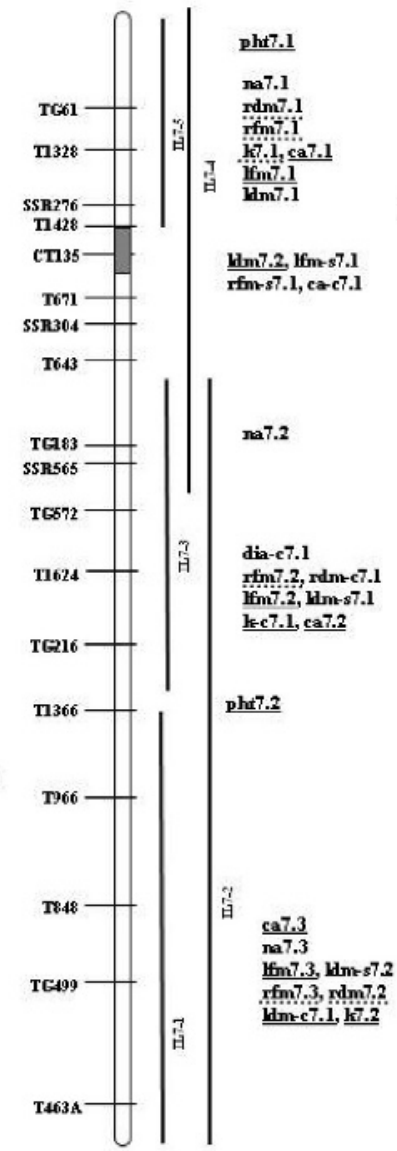

Chrom.7

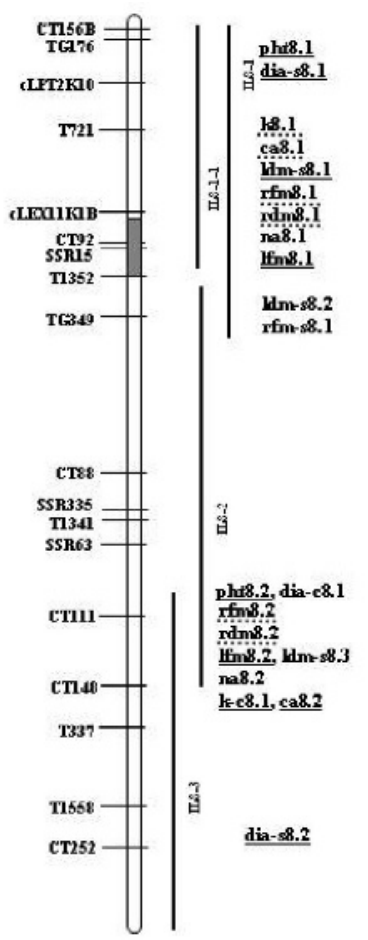

Chrom.8 the wild alleles for all of these loci were associated with increased stem diameter

One QTL was detected that controlled leaf number under both normal and stress conditions (Fig. 1). No loci were identified for this trait under control conditions and only one locus was detected for stress conditions. Like the other leaf number QTL, this locus had only a moderate effect on leaf number.

Leaf fresh mass was controlled by 22 QTL in both control and stress conditions (Fig. 1). Wild alleles for nearly all of these loci $(91 \%)$ were associated with increases in fresh mass. The greatest increases in leaf mass due to L. pennellii alleles were observed for lfm 2.1 (190 and $234 \%$ increases for control and stress conditions, respectively). In general, QTL had lesser effects under stress conditions as compared to control conditions. Only 3 loci were identified for leaf fresh mass under control conditions and 10 QTL were detected for leaf fresh mass in stress conditions. L. pennellii alleles for these loci were equally divided between those for increased and decreased mass. Overall, increases in leaf fresh mass associated with wild alleles under $\mathrm{NaCl}$ stress were moderate. 

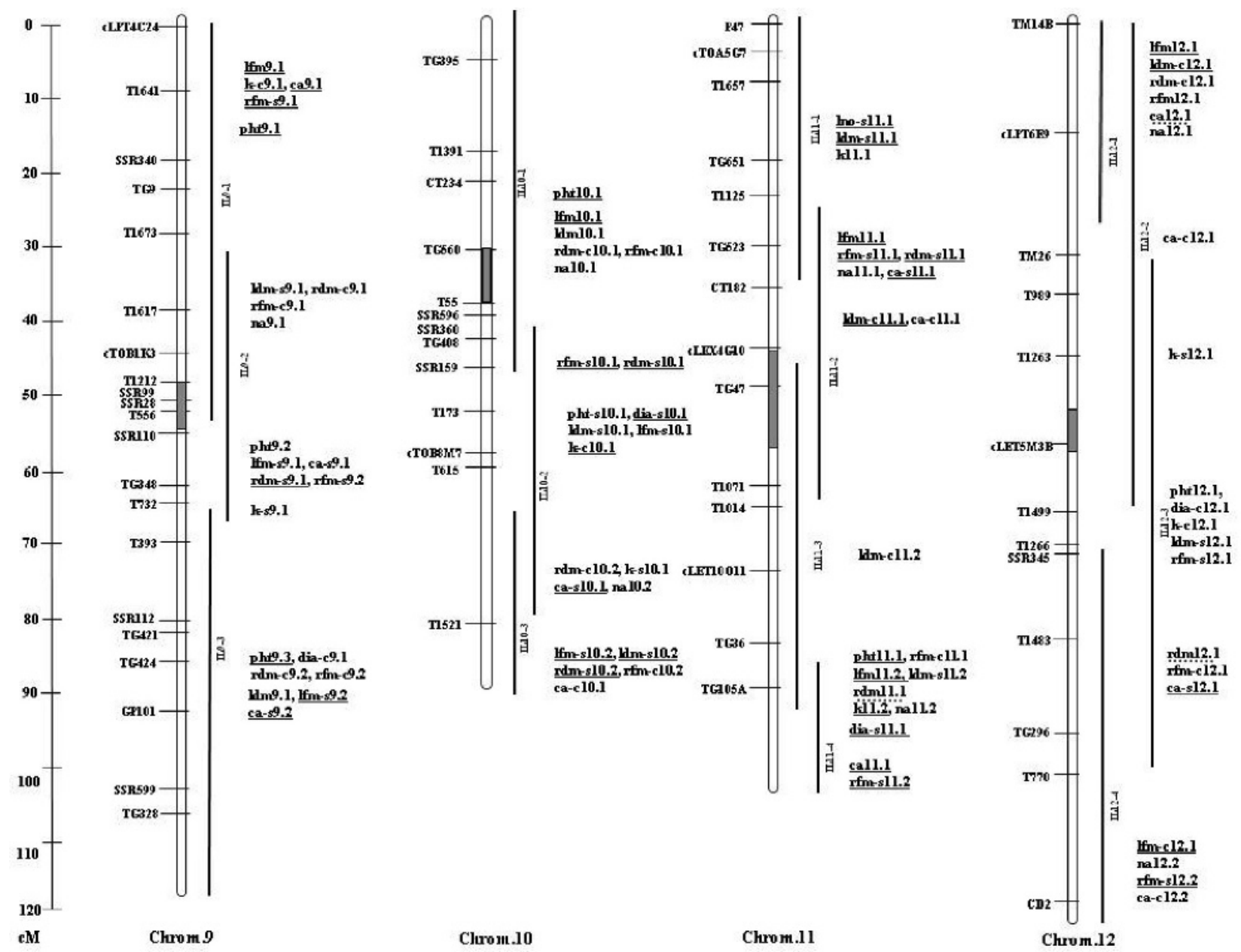

Fig. 1 (continued).

Seven QTL were identified that affected leaf dry mass under stress and non-stress conditions (Fig. 1). L. pennellii alleles were responsible for significant increases in leaf dry mass for only two loci. The greatest effect was observed for $l d m 2.1$ for which the wild allele increased leaf mass by 159 and $200 \%$ under control and stress conditions, respectively. A total of 12 loci were identified for leaf dry mass under control conditions, while 22 loci were detected for the trait under stress conditions. Increased dry mass under $\mathrm{NaCl}$ stress was specified by wild alleles for four loci with $l d m-s 11.1$ having the greatest effect, a $100 \%$ increase in mass as compared to M82.

Root fresh mass was associated with 10 QTL under both control and stress conditions (Fig. 1). For all but one locus, wild alleles were associated with a decrease in root mass when plants were grown in control conditions and an increase in mass when grown under stress. A total of 16 loci were identified for root fresh mass under control conditions. As with root dry mass, for all of these QTL, the L. pennellii alleles were associated with decreased root mass. Seventeen $\mathrm{NaCl}$-specific loci were also identified for root fresh mass. L. pennellii alleles for most
$(65 \%)$ of these QTL were associated with increased root mass under $\mathrm{NaCl}$ stress.

Eleven loci were identified that controlled root dry mass under stress and non-stress conditions (Fig. 1). Interestingly, L. pennellii alleles for most of the loci $(91 \%)$ were responsible for decreased root dry mass under control conditions and increased mass under $\mathrm{NaCl}$ stress. For five loci $(r d m 2.1, r d m 7.1, r d m 11.1, r d m 12.1)$, wild alleles were associated with increases in mass of more than $200 \%$ under stress conditions. Sixteen loci were identified for the trait specifically under control conditions. For all of these loci, the L. pennellii alleles were related with significant decreases in root mass. In contrast, for the 14 QTL that were detected for root dry mass only under stress conditions, $85 \%$ showed increased root mass associated with wild alleles. Three loci $(r d m-s 4.1, \quad r d m-s 10.1$ and $r d m-s 11.1)$ showed increases in root mass of more than $300 \%$ as compared to the $\mathrm{M} 82$ control grown under $\mathrm{NaCl}$ stress.

A total of 25 loci were identified for sodium content under both stress and non-stress growth (Fig. 1). For all of these QTL, L. pennellii alleles were associated with decreased sodium content in both environments. Wild 
alleles decreased sodium content by as much as $100 \%$ under control conditions and $98 \%$ under $\mathrm{NaCl}$ stress. In general, for each QTL greater effects were seen under non-stress conditions than when plants were grown with $\mathrm{NaCl}$. No sodium content QTL were detected specifically for control conditions and only one locus was specific for stress conditions.

A total of 12 loci were identified for potassium content under both experimental conditions (Fig. 1). The L. pennellii alleles for these loci showed every combination of effects. Ten loci were also identified for the trait only under control conditions. Wild alleles for these control-specific QTL were nearly always (90\%) associated with increased potassium levels. In addition, nine salt-specific loci were identified. For most (78\%) of these, the L. pennellii alleles were responsible for moderately decreased potassium content.

\section{Discussion}

Salt stress resulted in decreases in plant height, stem diameter, leaf number, leaf mass and root mass for both L. esculentum M82 and L. pennellii LA716. These changes were expected as it is known that plants tend to slow their growth in response to stress conditions (Kalefetoglu and Ekmekci 2005). With the exception of leaf mass, the reductions in the growth parameters were greater in M82 than in LA716. This difference was also expected as $\mathrm{LA} 716$ is tolerant to $\mathrm{NaCl}$ stress and therefore may be able to support a higher growth rate than M82 (salt sensitive) when exposed to $\mathrm{NaCl}$ stress. In addition, it was observed that the reduction in leaf mass was much greater than that of root mass in LA716. A similar response of tomato to salt stress was observed by Foolad (1997) who found that salt stress inhibited shoot growth more than root growth.

Although L. pennellii introgressions were generally associated with lower root mass than M82, $58 \%$ of the ILs produced more roots under $\mathrm{NaCl}$ stress than under control conditions. This may indicate that L. pennelliiderived salt tolerance involves the production of more roots as a strategy to absorb more water in soil with low osmotic potential. An increased root to shoot ratio has been reported to be associated with $\mathrm{NaCl}$ stress in tomato (Maggio et al. 2004). The root to shoot ratio of M82 decreased by 2.2 and 2.5-fold for wet and dry mass, respectively, while that of LA716 increased by 2.5 and 3.5-fold, respectively. The ILs behaved like LA716 with only eight lines showing decreased root to shoot ratios under $\mathrm{NaCl}$ stress.

Salt stress resulted in increased sodium content in nearly all of the plants tested, however, the magnitude of the increase in L. pennellii LA716 (5.5-fold) was much greater than that seen in L. esculentum M82 (2.7-fold). According to Foolad (1997), L. esculentum responds to $\mathrm{NaCl}$ stress by excluding sodium ions. At high $\mathrm{NaCl}$
Fifteen QTL were detected for calcium content when plants were grown in stress and non-stress environments (Fig. 1). For most (80\%) of these loci, L. pennellii alleles were related with increased calcium content as compared to M82. While the effects of the QTL were moderate under control conditions, under $\mathrm{NaCl}$ stress L. pennellii alleles were associated with very dramatic increases in calcium content with seven loci showing increases of more than $500 \%$ as compared to M82. A total of 13 QTL were identified for control-specific accumulation of calcium. Thirteen NaCl-specific QTL were also detected for calcium content. For all but two of these loci, L. pennellii alleles were responsible for very large increases in calcium content similar to those seen for the QTL identified under both stress and non-stress conditions. The greatest increases were observed in $c a-s 6.2$ and $c a-s 3.1,700$ and $713 \%$, respectively.

concentrations, however, this system breaks down. It is difficult to determine if $\mathrm{NaCl}$ exclusion was occurring in our experiment as M82 had much higher contents of sodium than LA716 even under control conditions. Only two ILs showed decreased sodium content under $\mathrm{NaCl}$ stress, IL2-1 and IL11-3. If these findings are verified by further experiments, they may indicate that these two lines are somehow deficient for sodium uptake. Such results would indicate that $L$. pennellii contains mutations for ion uptake/transport on chromosomes 2 and 11.

Potassium content of M82, LA716 and most of the ILs decreased under $\mathrm{NaCl}$ stress. Potassium and sodium ions rely on very similar systems for entry into plant cells including $\mathrm{Na}^{+}$-coupled $\mathrm{K}^{+}$transporters, nonselective monovalent cation carriers and ion channels that mediate both $\mathrm{K}^{+}$and $\mathrm{Na}^{+}$transport (Cushman 2001). High affinity $\mathrm{K}^{+}$transporters have been identified in Arabidopsis that are blocked by high concentrations of sodium ions. Thus, growth in saline soils may lead to reduced uptake of potassium by plants. Potassium is required for osmotic adjustment to salinity and the activation of many enzymes which can also bind sodium ions (Shabala and Cuin 2007). If sodium ions are bound, normal metabolism is disrupted. Thus, the maintenance of a high $\mathrm{K}^{+} / \mathrm{Na}^{+}$ratio in the cytosol is necessary for normal plant growth under $\mathrm{NaCl}$ stress.

Plants also require high concentrations of calcium for optimum growth under both normal and stress conditions (Demidchik and Maathuis 2007). In a saline environment, calcium can interfere with the movement of sodium ions into the plant through nonselective cation channels that are voltage independent (Demidchik and Maathuis 2007). In addition, calcium is an important signaling molecule and its increase in response to salinity is thought to trigger activation of $\mathrm{Na}^{+} / \mathrm{H}^{+}$antiporters (Munns and Tester 2008). It has also been reported that salt tolerance 
in L. esculentum is associated with the maintenance of calcium uptake and the exclusion of sodium ions (Ashraf 2004). In our study, calcium contents of M82 and LA716 were decreased by $\mathrm{NaCl}$ stress, however, the ILs had a mixed response with nearly equal numbers showing increases and decreases.

Salt tolerance is only partially determined by alterations in growth and ion concentration and it is possible that tolerance may be achieved in more than one way for these different parameters. Thus, different growth and ion exclusion, sequestration or uptake strategies may give the same result: salt tolerance. For example, some individuals may express tolerance as the ability to reduce shoot growth while maintaining root mass. Other plants may exhibit tolerance as the ability to continue shoot growth despite $\mathrm{NaCl}$ stress. Similarly when ion content is considered, salt tolerance may be the result of several factors either singly or in combination. Thus, exclusion of sodium ions, maintenance of potassium uptake in saline soils and/or increased calcium uptake are all strategies that may help a plant achieve salt tolerance.

Based on QTL analysis, the greatest increase in plant height under $\mathrm{NaCl}$ stress was conferred by a locus shared by IL1-3 and IL1-4. This QTL was responsible for an $87 \%$ increase in plant height when the IL was compared to M82. IL11-1 and IL11-2 are also of special interest because these two lines harbored the most important loci for leaf number, leaf dry mass and root dry and fresh mass. L. pennellii alleles for these loci were responsible for 100 and $640 \%$ increases in leaf and root dry mass, respectively, as compared to $\mathrm{M} 82$ under $\mathrm{NaCl}$ stress. Both of these ILs also contained a QTL for calcium content under $\mathrm{NaCl}$ stress for which the wild allele conferred a $363 \%$ increase as compared to M82. In terms of ion content, IL2-5 is of interest because it harbors a locus for which the $L$. pennellii allele specified $83 \%$ lower sodium content than M82 under salinity. IL6-3 was associated with loci for both potassium and calcium content under $\mathrm{NaCl}$ stress. The wild alleles for these loci or pleiotropic locus were associated with 74 and $700 \%$ higher potassium and calcium contents, respectively.

Examination of Fig. 1 shows that many more QTL and ILs of interest to plant physiologists and breeders were identified in this work. Thus, this research may serve as a starting point for deeper investigations into the genetic control of and relationship between growth and ion responses to salt stress. For example, an IL with a locus or loci of interest may be selected and used to develop a population for fine mapping of the gene/genes responsible. Such populations can also be used for further introgression of QTL to breeding lines which is facilitated by the fact that the ILs contain single, welldefined introgressions in the cultivated tomato background. Such research may lead to the development of tomato cultivars with improved salt tolerance and a greater understanding of this increasingly important trait.

\section{References}

Ashraf, M.: Some important physiological selection criteria for salt tolerance in plants. - Flora 199: 361-370, 2004.

Borsani, O., Valpuesta, V., Botella, M.A.: Developing salt tolerant plants in a new century: a molecular biology approach. - Plant Cell Tissue Organ Cult. 73: 101-115, 2003.

Chapman, H.D., Pratt, P.F.: Methods of Analysis for Soils, Plants and Waters. - University of California, Berkeley 1961.

Cushman, J.C.: Osmoregulation in plants: implications for agriculture. - Amer. Zool. 41: 758-769, 2001.

Dasgan, H.Y., Aktas, H., Abak, K., Cakmak, I.: Determination of screening techniques to salinity tolerance in tomatoes and investigation of genotype responses. - Plant Sci. 163: 695$703,2002$.

Demidchik, V., Maathuis, F.J.M.: Physiological roles of nonselective cation channels in plants: from salt stress to signaling and development. - New Phytol. 175: 387-404, 2007.

Epstein, E.: Mineral Nutrition of Plants: Principles and Perspectives. - John Wiley \& Sons, New York 1972.

Eshed, Y., Zamir, D.: An introgression line population of Lycopersicon pennellii in the cultivated tomato enables the identification and fine mapping of yield-associated QTL. Genetics 141: 1147-1162, 1995.

Foolad, M.R.: Genetic analysis of salt tolerance during

vegetative growth in tomato, Lycopersicon esculentum Mill. - Plant Breed. 115: 245-250, 1996.

Foolad, M.R.: Genetic basis of physiological traits related to salt tolerance in tomato, Lycopersicon esculentum Mill. Plant Breed. 116: 53-58, 1997.

Foolad, M.R.: Recent advances in genetics of salt tolerance in tomato. - Plant Cell Tissue Organ Cult. 76: 101-119, 2004.

Frary, A., Gol, D., Keles, D., Okmen, B., Pinar, H., Sigva, H.O., Yemenicioglu, A., Doganlar, S.: Salt tolerance in Solanum pennellii: antioxidant response and related QTL. - BMC Plant Biol. 10: 58-68, 2010.

Juan, M., Rivero, R.M., Romero, L., Ruiz, J.M.: Evaluation of some nutritional and biochemical indicators in selected saltresistance tomato cultivars. - Environ. exp. Bot. 54: 193$201,2005$.

Kalefetoglu, T., Ekmekci, Y.: The effects of drought on plants and tolerance mechanisms. - Gazi Univ. J. Sci. 18: 723-740, 2005.

Maas, E.V.: Salt tolerance of plants. - Appl. Agr. Res. 1: 12-26, 1986.

Maggio, A., De Pascale, S., Angelino, G., Ruggiero, C., Barbieri, G.: Physiological response of tomato to saline irrigation in long-term salinized soils. - Eur. J. Agron. 21: 149-159, 2004.

Mittova, M., Guy, M., Tal, M., Volokita, M.: Salinity upregulates the antioxidative system in root mitochondria and 
peroxisomes of the wild salt-tolerant tomato species Lycopersicon pennellii. - J. exp. Bot. 55: 1105-1113, 2004.

Mittova, M., Theodoulou, F.L., Kiddle, G., Gomez, L., Volokita, M., Tal, M., Foyer, C.H., Guy, M.: Coordinate induction of glutathione biosynthesis and glutathionemetabolizing enzymes is correlated with salt tolerance in tomato. - FEBS Lett. 554: 417-421, 2003.

Mittova, V., Guy, M., Tal, M., Volokita, M.: Response of the cultivated tomato and its wild salt-tolerant relative Lycopersicon pennellii to salt-dependent oxidative stress:increased activities of antioxidant enzymes in root plastids. - Free Radical Res. 36: 195-202, 2002.

Munns, R., Tester, M.: Mechanisms of salinity tolerance. Annu. Rev. Plant Biol. 59: 651-681, 2008.

Rousseaux, M.C., Jones, C.M., Adams, D., Chetelat, R., Bennett, A., Powell, A.: QTL analysis of antioxidants in tomato using Lycopersicon pennellii introgression lines. Theor. appl. Genet. 111: 1396-1408, 2005.

Shabala, S., Cuin, T.A.: Potassium transport and plant salt tolerance. - Physiol. Plant. 133: 651-669, 2007.

Shalata, A., Mittova, V., Volokita, M., Guy, M., Tal, M.: Response of the cultivated tomato and its wild salt-tolerant relative Lycopersicon pennellii to salt-dependent oxidative stress: the root antioxidative system. - Physiol. Plant. 112: 487-494, 2001.

Shalata, A., Tal, M.: The effect of salt stress on lipid peroxidation and antioxidants in the cultivated tomato and its wild salt-tolerant relative Lycopersicon pennellii. Physiol. Plant. 104: 169-174, 1998.

Tal, M., Shannon, M.C.: Salt tolerance in the wild relatives of the cultivated tomato: responses of Lycopersicon esculentum, L. cheesmanii, L. peruvianum, S. pennellii and F1 hybrids to high salinity. - Aust. J. Plant. Physiol. 10: 109-117, 1983.

Xiong, L., Zhu, J.-K.: Salt tolerance. - In: Somerville, C, Meyerowitz, E. (ed.): The Arabidopsis Book. American Society of Plant Biologists, Rockville 2002. 